\title{
Pharmaceutical/food grade titanium dioxide particles are absorbed into the bloodstream of human volunteers
}

Laetitia C. Pele ${ }^{1}$, Vinay Thoree ${ }^{1}$, Sylvaine FA Bruggraber ${ }^{1}$, Dagmar Koller ${ }^{1}$, Richard PH Thompson? Miranda C. Lomer ${ }^{2}$ and Jonathan J. Powell ${ }^{* *}$

\begin{abstract}
Background: Exposure to persistent engineered nano and micro particles via the oral route is well established. Animal studies have demonstrated that, once ingested, a small proportion of such particles translocate from the gastrointestinal tract to other tissues. Exposure to titanium dioxide is widespread via the oral route, but only one study has provided indirect evidence (total titanium analyses) of absorption into the blood stream in humans. We sought to replicate these observations and to provide additional evidence for particulate uptake.

Findings: Human volunteers with normal intestinal permeability were orally administered $100 \mathrm{mg}$ pharmaceutical/food grade titanium dioxide. Blood samples were collected from 0.5 to $10 \mathrm{~h}$ post ingestion and analysed for the presence of reflectant bodies (particles) by dark field microscopy, and for total titanium by inductively coupled plasma mass spectrometry (ICP-MS). Blood film analyses implied early absorption of particles $(2 \mathrm{~h})$ with a peak maximum at $6 \mathrm{~h}$ following ingestion. The presence of these reflectant particles in blood roughly mirrored the levels of total titanium by ICP-MS, providing good evidence for the latter being a measure of whole particle (titanium dioxide) absorption.

Conclusions: This study shows that a fraction of pharmaceutical/food grade titanium dioxide is absorbed systemically by humans following ingestion. It confirms that at least two routes of particle uptake may exist in the human gut- one proximal and one distal. Further work should quantify human exposure and uptake of such persistent particles.
\end{abstract}

Keywords: Titanium dioxide, Particles, Absorption, Blood stream

\section{Background}

Oral exposure to non-biological nano- and micro- particles from the diet, environment, and man-made health and hygiene products, is now well established [1]. Persistent particles, meaning those that are not broken down easily by the gastrointestinal tract or intracellularly, have been the subject of particular attention as animal studies indicate that they may migrate from the gut mucosa to draining lymph nodes and then become translocated to most tissues of the body [2]. However, there is much less evidence in man. Examination of surgical and post-mortem specimens has confirmed that there is retention of engineered particles in the human intestinal

\footnotetext{
* Correspondence: jonathan.powell@mrc-hnr.cam.ac.uk

${ }^{1}$ Medical Research Council Human Nutrition Research, Elsie Widdowson Laboratory, Fulbourn Road, Cambridge CB1 9NL, UK

Full list of author information is available at the end of the article
}

mucosa, especially the Peyer's patch lymphoid follicles [3-5]. Using large micron-sized biological particles (such as starch and pollen), Volkeimer has convincingly shown their appearance in the blood stream following ingestion by humans. With histological studies in rodents he developed the concept of 'persorption' whereby holes in the tips of intestinal villi allow the ingress of particles $[6,7]$. This and other mechanisms of uptake by the gut have been studied and reviewed by us [1] and others $[8,9]$. Oral absorption of particulate titanium dioxide $\left(\mathrm{TiO}_{2}\right)$, a common food additive and excipient used in nutraceuticals, pharmaceuticals and toothpaste [10], has been especially well studied in animals [11], but barely so in man. To date, only Bockmann et al. have shown in humans that measurable increases in total titanium (Ti) levels occur in the blood stream following ingestion of capsules containing $\mathrm{TiO}_{2}$ particles [12]. Given 
that $\mathrm{TiO}_{2}$ is so resistant to dissolution, and that it accumulates in human intestinal cells [3-5], it is probable that Bockmann et al. were showing direct particle uptake, although this was not measured. Despite high interest on the use of $\mathrm{TiO}_{2}$ particles and their potential impact following acute and chronic exposure, investigative studies looking at $\mathrm{TiO}_{2}$ absorption in humans have only been reported once, in 2015 [13], since the initial published findings in the year 2000 [12]. However, in the recent work, high baseline values appear to have prevented observations on the appearance of $\mathrm{Ti}$ in the circulation following ingestion of $\mathrm{TiO}_{2}$ [13]. Here, in a simple pilot study that used pharmaceutical and food grade anatase $\mathrm{TiO}_{2}$ particles, we sought to corroborate the earlier findings of Bockmann et al. and, further, to confirm that the increased levels of $\mathrm{Ti}$ observed in blood are due to whole particle uptake into the circulation. As single particle analysis was not fully developed for quantitative analysis of blood samples, we chose to use a simple semi-quantitative method for particle detection, namely dark field microscopy. $\mathrm{TiO}_{2}$ readily reflects light so particles can easily be detected in complex biological samples using this technique [14]. A $100 \mathrm{mg} \mathrm{TiO}_{2}$ oral dose was chosen as this is to be at the upper end of the normal daily intake of engineered particles by humans [10], and the sampling intervals were similar to those of Bockmann et al. (i.e. between 0-10 h). We additionally determined whether blood Ti levels mirrored the presence of reflectant particles in blood as together they should provide unambiguous evidence of $\mathrm{TiO}_{2}$ particle absorption.

\section{Methods}

Preparation of permeability solution and $\mathrm{TiO}_{2}$ capsules

To assess that the volunteers had normal intestinal permeability, an iso-osmolar test sugar solution $(300 \mathrm{mmol} / \mathrm{kg})$ containing $0.5 \mathrm{~g}$ D-xylose, $1 \mathrm{~g}$ L-rhamnose, $0.2 \mathrm{~g}$ 3-Omethyl-D-glucose and $5 \mathrm{~g}$ lactulose was prepared and $100 \mathrm{ml}$ administered orally per subject. Gelatine capsules, containing $50 \mathrm{mg}$ pharmaceutical/food grade anatase $\mathrm{TiO}_{2}$ (Kronos $^{\circ} 1171$; reported manufacturer's d50 of $260 \mathrm{~nm}$, Fagron UK,) were manufactured by St Thomas' Hospital Pharmacy (London).

\section{Conduct of the study}

Following ethical approval (EC01/037) and informed consent, eight healthy (self-reported) volunteers were recruited; seven completed the study as blood could not be withdrawn from the cannula of one subject. First, subjects were provided with the permeability solution, $1 \mathrm{l}$ of deionised water and a $2 \mathrm{l}$ urine bottle containing the preservative thiomerasol. Subjects were asked not to consume any dairy products from lunchtime the day before the test. At 7.00 am following an overnight fast, subjects emptied their bladders and provided a baseline urine sample in $50 \mathrm{ml}$ universal tubes. They then ingested the $100 \mathrm{ml}$ test sugar solution and during the following two hours they were only allowed to drink deionised water. Urine was collected thereafter for $5 \mathrm{~h}$ in the $2 \mathrm{l}$ urine bottles (i.e. until $12.00 \mathrm{pm})$.

At $9.00 \mathrm{am}$, a peripheral venous cannula was inserted and a $5 \mathrm{ml}$ baseline blood sample taken. Immediately following this, subjects ingested two capsules each containing $50 \mathrm{mg}$ of pharmaceutical/food grade $\mathrm{TiO}_{2}$ (total $100 \mathrm{mg}$ ) with $250 \mathrm{ml}$ water - one capsule was taken immediately following the other. Blood samples were then taken at baseline (0), at $30 \mathrm{~min}$, and at 1, 1.5, 2, 3, 6, 8 and $10 \mathrm{~h}$ post $\mathrm{TiO}_{2}$ ingestion. Blood samples were heparinised and analysed as described below.

Normal drinking water was provided throughout the study and meals, free from added $\mathrm{TiO}_{2}$, were provided at 10.00 am (Breakfast: wholemeal toast with salted butter and strawberry jam), $1.00 \mathrm{pm}$ (Lunch: chicken and green pepper stir fry with boiled rice, fresh fruit and a small packet of plain crisps) and $4.00 \mathrm{pm}$ (Mid-afternoon snack: chocolate biscuit and/or fresh fruit). Tea and coffee with milk and/or sugar were allowed as desired from 11 am onwards.

\section{Identification of $\mathrm{TiO}_{2}$ in blood by dark field microscopy}

One drop of blood $(\sim 45 \mu \mathrm{l})$ from the syringe following sampling (i.e. non-heparinised) was placed on a clean, freshly opened glass slide. Superfrost plus slides were used to allow cell adherence. The blood was spread thinly with a clean slide to aid monolayer formation and a cover slip was then sealed in place with nail vanish to prevent sample drying. The slide was examined by light microscopy first at x 100 magnification and then $\mathrm{x} 400$. Random areas were visualised at $\mathrm{x} 400$ using a dark-field condenser to allow the titanium dioxide particles to be easily observed as bright white discrete particles in contrast, for example, to cell debris which was much less bright and less punctate, and generally translucent. The estimation of particles within each field was based on four reflectance grades; namely $0,1,2$ and 3 , and the operator was blinded to sample codes. A reflectance grade of 0 indicated 5 or less particles/field, a grade of 1 showed 5 to 10 particles/field, a grade of 2 showed 10 to 20 particles/field, and a grade of 3 indicated $>20$ particles/field. Reflectance grades, rather than absolute numbers, were used for rapid data acquisition and because of the semi-quantitative nature of detection. Visualisation of $\mathrm{TiO}_{2}$ particles by dark field microscopy could only be carried out in five out of seven subjects due to clotting of blood in two subjects.

\section{Measurement of Ti by Inductively Coupled Plasma- Mass Spectrometry (ICP-MS)}

Aliquots of collected heparinised blood samples were acid digested using sub-boiling nitric acid diluted with Milli-Q 
water and high-purity hydrogen peroxide [15]. Total $\mathrm{Ti}$ concentrations were determined by High-Resolution ICPMS at the Department of Physical and Analytical Chemistry, University of Oviedo, Spain, using an Element 2 (Thermo Fisher Scientific, Waltham, MA, USA) working at medium resolution $(\mathrm{RS}=4000)$ to analyse the isotope of ${ }^{47} \mathrm{Ti}[15,16]$. For quantification, the method of isotope dilution was applied [17]. Measurement of Ti was carried for time points $0-10 \mathrm{~h}$ except in two subjects where samples at $8 \mathrm{~h}$ in both, and $10 \mathrm{~h}$ in one, could not be collected.

\section{Statistics}

The estimation of particle numbers present in blood films and the levels of $\mathrm{Ti}$ following ingestion of $\mathrm{TiO}_{2}$ were assessed using a two-tailed paired t-test. The relationship between reflectance grades (i.e. $\mathrm{TiO}_{2}$ particles within blood) and the levels of Ti measured by ICP-MS was determined using a Spearman correlation test. For all tests, significance was taken at $\mathrm{p}<0.05$.

\section{Results and discussion}

The seven subjects had normal gut permeability and absorption characteristics of the different sugars based upon their urinary excretion data (Fig. 1). Some of the ingested $\mathrm{TiO}_{2}$ was absorbed directly into the blood stream in its particulate form based upon dark field microscopy (Figs. 2 and 3a). Positive signals were assumed to be $\mathrm{TiO}_{2}$ particles since no other sources of particles were provided (i.e. the subjects only ingested $\mathrm{TiO}_{2}$ particles and the lunch provided had no particulate additives). As such, whilst occasional positive signals were noted at baseline (i.e. bright discrete particles), observations always numbered less than 5 per field (i.e. scored 0; Figs. 2 and 3a). Significant increases in positive signals were observed in the blood films from $2 \mathrm{~h}$ onwards (Figs. 2 and 3a, $p<0.05$ ). Dark field microscopy findings were roughly mirrored by ICP-MS measurements of

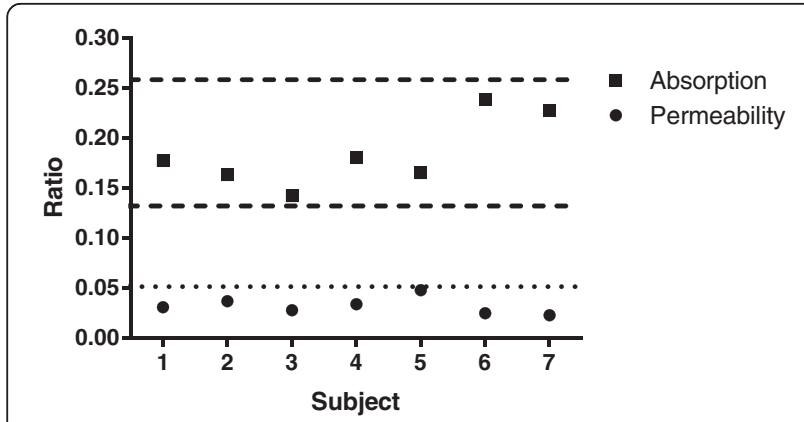

Fig. 1 Intestinal permeability and absorption. Small molecule permeability (black circles; lactulose:rhamnose excretion) and absorption (black squares; rhamnose:3-O-methyl glucose excretion) ratios. The reference ranges for permeability (dotted line) and absorption (dashed line) are ratios of $<0.05$, and $0.132-0.258$, respectively

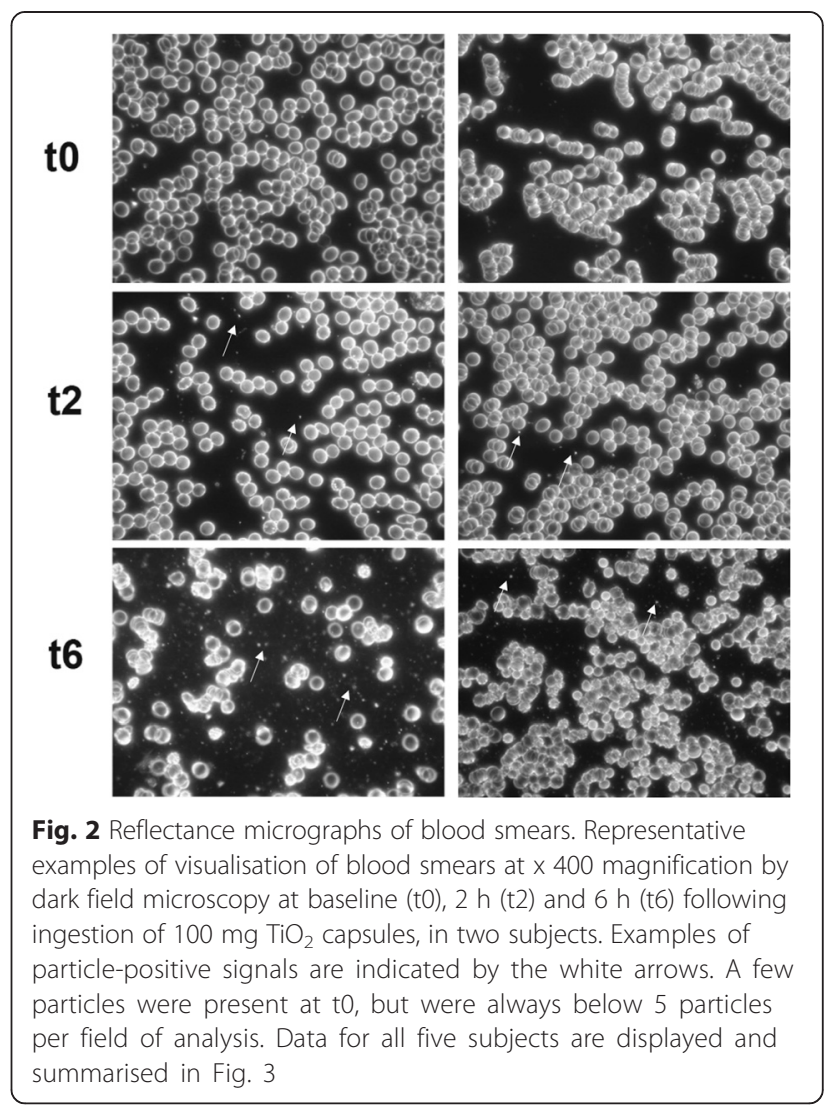

total Ti within the same blood samples (Fig. 3b, c, t2-t10), with both techniques demonstrating a peak of absorption at $6 \mathrm{~h}$ post ingestion (Fig. 3a, b; $p<0.05$ ). Indeed, there was a positive correlation between reflectance grades and total Ti levels (Fig. 3c, $p=0.0058$ and $r=0.5803$ ).

Our current findings substantiate those of Bockmann et al., in which a comparable trial design demonstrated a similar pattern of titanium loading into the blood stream of human subjects following the ingestion of $\mathrm{TiO}_{2}$ [12]. However, we now show that these total Ti signals by ICP can be reasonably attributed to the actual absorption of whole particles $\left(\right.$ i.e. $\left.\mathrm{TiO}_{2}\right)$. Confirmation that the direct uptake of particulates occurs early (Figs. 2 and 3a), and peaks late (Fig. 3a), has some important implications for understanding oral particle exposure to humans. First, it confirms that persistent particles (i.e. those that evade gut and cellular digestion) can be taken up systemically in man, confirming the results of many animal studies and models of uptake [18-20]. Secondly, it provides further evidence to agree with Bockmann's observations that, in humans, a bimodal pattern of particle uptake occurs: it starts early (i.e. visible by $2 \mathrm{~h}$ following ingestion) but peaks later (i.e. $6 \mathrm{~h}$ following ingestion). If so, this pattern may be explained by some absorption in the proximal small intestine (duodenum/jejunum) [1,7] with later Peyer's patch uptake in the more distal small intestine (ileum) [1]. Peyer's patches are 


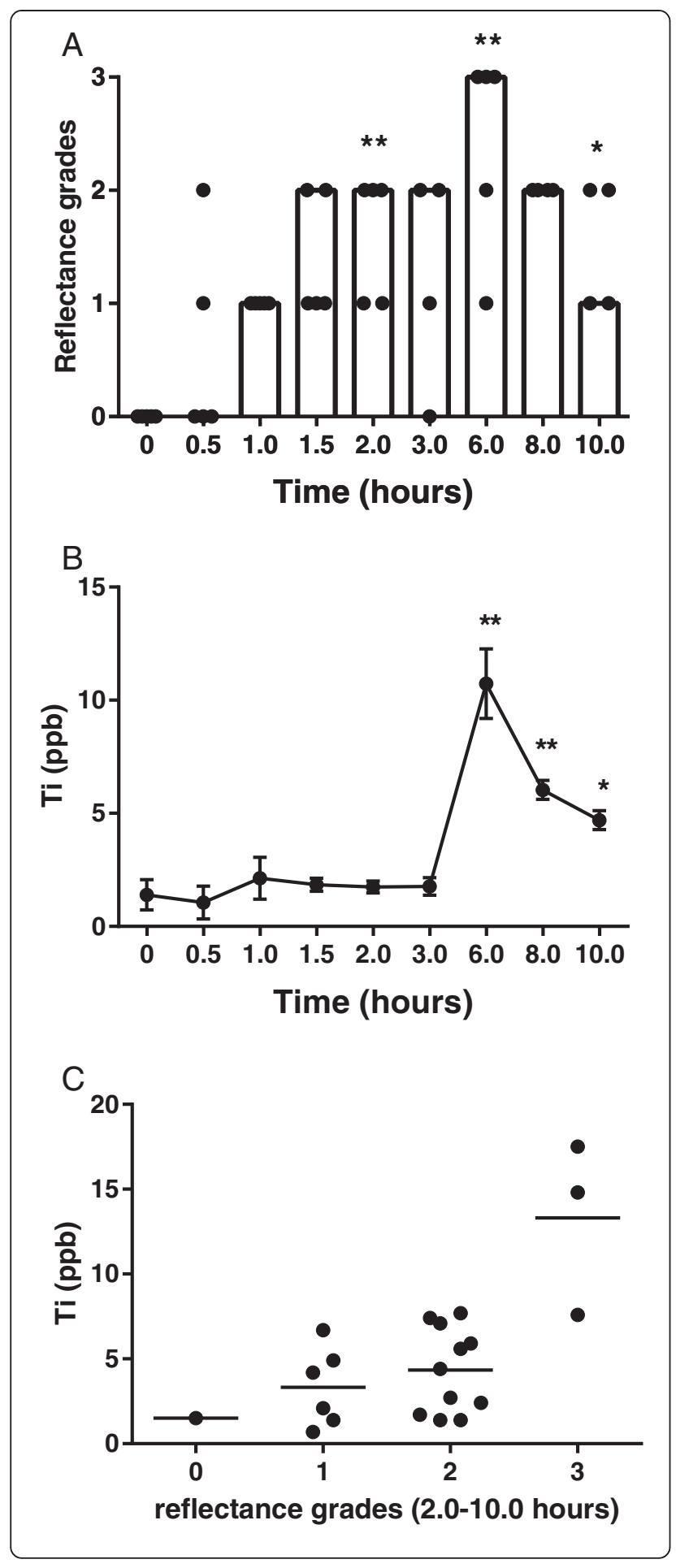

Fig. 3 Absorption of $\mathrm{TiO}_{2}$ particles into the blood stream. a- Grading of the frequency of discrete particulate reflectance in blood smears by dark field microscopy following ingestion of $100 \mathrm{mg} \mathrm{TiO})_{2}$ capsules $(n=5$ subjects). Data are plotted as mode (column) and individual grades (closed circles). ${ }^{*} p<0.05$ and ${ }^{* *} p<0.01$ vs time point 0 , two-tailed paired $t$ test. $\mathbf{b}$ - Total Ti levels (ppb) measured by ICP-MS in the same blood samples as above with two further subjects (total seven). Data are represented as mean $+/-$ SEM. ${ }^{*} p<0.05$ and ${ }^{* *} p<0.01$ vs time point 0 , two-tailed paired $t$ test. $\mathbf{c}$ - Correlation between reflectance grades and total Ti levels in blood for the five complete subjects only. Pearson correlation $p=0.0058$ and $r=0.5803$

intestinal lymphoid follicles lined with specialised microfold (M) cells that specifically and avidly capture small particles. How such non-biological particles are then distributed is not clear, although local cellular uptake of the particles may occur (i.e. in mucosal antigen presenting cells [21]), with the potential for translocation to the mesenteric lymph nodes and then beyond, as well as distribution to other organs as shown in animal studies. For the latter, bloodborne transport must occur, as we confirm, although whether the particles are transported within or outside of immune cells requires confirmation.

The route of putative proximal absorption is less clear. As noted earlier, the term persorption has been coined byand the phenomenon well described by- Volkeimer [7]. Additionally, the sporadic occurrence of small M-cell rich areas throughout the small intestine [22] may also provide ports of entry for particles, or the nano fraction of the ingested particles could pass through regular epithelial cells to underlying dendritic cells, as recently described [23]. It was not our intention to size the absorbed $\mathrm{TiO}_{2}$ particles and hence we did not measure the size distribution of the $\mathrm{TiO}_{2}$ administered. Nevertheless, a recent publication investigating the same $\mathrm{TiO}_{2}$ particles quotes a primary particle size distribution of 88.9-200.6 nm (d10-d84) [24] which is smaller than the stated manufacturer's d50 of 260 $\mathrm{nm}$, perhaps because the latter also measured small agglomerates during analysis. More importantly the particles represent a 'real life' scenario of what humans can be exposed to, either in food or pharmaceuticals, and clearly a fraction of it will be nano-sized [11]. Further work will need to confirm the proposed proximal intestinal uptake of particles, in humans, and the underlying mechanisms, but a preference for penetration by the nano-sized fraction should not be ruled out as this is seen in rodents $[18,19]$.

Finally, although the ingestion of $100 \mathrm{mg} \mathrm{TiO}{ }_{2}$ exceeds human intestinal exposure as a single dose, it falls within daily limits [10] and higher dosing facilitates analytical detection. Therefore, whilst absolute particle absorption may be lower in the general population than observed here, the percentage absorbed is likely to be higher. Indeed, Powell and colleagues have estimated that adult humans may absorb $10^{12} \mathrm{TiO}_{2}$ particles/person/day [25]. Further quantification work of titanium dioxide absorption at 
different doses, and translation to particle numbers and sizes is now needed.

The recent implementation of new software for single particle ICP-MS analysis [26], advancements of hyphenated techniques like field flow fractionation [27] and hydrodynamic chromatography [28] combined with ICP-MS and the emergence of a triple quadrupole ICP-MS [29] should all aid the development of quantitative techniques to help assess human exposure to $\mathrm{TiO}_{2}$.

In summary, we show here that a portion of ingested pharmaceutical and food grade $\mathrm{TiO}_{2}$, to which humans are very frequently orally exposed, is directly absorbed, as particles, into the blood stream of healthy volunteers. The seemingly early absorption and late peak of uptake point towards two distinct periods and perhaps routes of uptake: one early in the proximal small intestine and one late in the distal small intestine. Quantitative measurements are now merited to estimate real human exposures.

\section{Abbreviations}

ICP-MS: Inductively coupled plasma-mass spectrometry; Ti: Titanium;

$\mathrm{TiO}_{2}$ : Titanium dioxide.

\section{Competing interests}

The authors declare that they have no competing interests.

\section{Authors' contributions}

JJP and MCL developed the overall hypothesis and specific study design and, with $L C P$, were responsible for data interpretation. VT developed the techniques for the semi-quantitation of $\mathrm{TiO}_{2}$ in blood smears. SFAB and DK were responsible for the coordination and logistics of blood samples for analysis by ICP-MS, and for the interpretation of resulting ICP-MS data. LCP with JJP wrote the paper. RPHT provided advice and support in project design and implementation. All authors contributed to data interpretation and to the writing and critical review of the manuscript. All authors read and approved the final manuscript.

\section{Acknowledgements}

The authors would like to acknowledge the UK Medical Research Council (Grant number U105960399) for their continued support. The authors also wish to thank St Thomas' Hospital Pharmacy for the manufacture of $\mathrm{TiO}_{2}$ capsules, Maria Montes-Bayón and colleagues from the Department of Physical and Analytical Chemistry, University of Oviedo for the analyses of Titanium by ICP-MS and the statistical team at MRC-HNR for guidance in statistical analyses.

\section{Author details \\ ${ }^{1}$ Medical Research Council Human Nutrition Research, Elsie Widdowson Laboratory, Fulbourn Road, Cambridge CB1 9NL, UK. '2Department of Gastroenterology, Guys and St Thomas' NHS Foundation Trust, St Thomas' Hospital, London SE1 7EH, UK.}

Received: 31 January 2015 Accepted: 24 August 2015

Published online: 02 September 2015

\section{References}

1. Powell JJ, Faria N, Thomas-McKay E, Pele LC. Origin and fate of dietary nanoparticles and microparticles in the gastrointestinal tract. J Autoimmun. 2010;34(3):J226-33. doi:10.1016/j.jaut.2009.11.006.

2. Lin Z, Monteiro-Riviere NA, Riviere JE. Pharmacokinetics of metallic nanoparticles. Wiley Interdiscip Rev Nanomed Nanobiotechnol. 2014. doi:10.1002/wnan.1304

3. Powell JJ, Ainley CC, Harvey RS, Mason IM, Kendall MD, Sankey EA, et al. Characterisation of inorganic microparticles in pigment cells of human gut associated lymphoid tissue. Gut. 1996;38(3):390-5.
4. Shepherd NA, Crocker PR, Smith AP, Levison DA. Exogenous pigment in Peyer's patches. Hum Pathol. 1987;18(1):50-4.

5. Urbanski SJ, Arsenault AL, Green FH, Haber G. Pigment resembling atmospheric dust in Peyer's patches. Mod Pathol. 1989;2(3):222-6.

6. Volkheimer $\mathrm{G}$. Passage of particles through the wall of the gastrointestinal tract. Environ Health Perspect. 1974;9:215-25.

7. Volkheimer G. Persorption of microparticles. Pathologe. 1993;14(5):247-52.

8. Awaad A, Nakamura M, Ishimura K. Imaging of size-dependent uptake and identification of novel pathways in mouse Peyer's patches using fluorescent organosilica particles. Nanomedicine. 2012;8(5):627-36. doi:10.1016/j.nano. 2011.08.009.

9. Frohlich $E$, Roblegg E. Models for oral uptake of nanoparticles in consumer products. Toxicology. 2012;291(1-3):10-7. doi:10.1016/j.tox.2011.11.004.

10. Lomer MC, Hutchinson C, Volkert S, Greenfield SM, Catterall A, Thompson RP, et al. Dietary sources of inorganic microparticles and their intake in healthy subjects and patients with Crohn's disease. Br J Nutr. 2004:92(6):947-55.

11. Jovanovic B. Critical review of public health regulations of titanium dioxide, a human food additive. Integr Environ Assess Manag. 2015;11(1):10-20. doi:10.1002/ieam.1571.

12. Bockmann J, Lahl H, Eckert T, Unterhalt B. Blood titanium levels before and after oral administration titanium dioxide. Pharmazie. 2000;55(2):140-3.

13. Jones K, Morton J, Smith I, Jurkschat K, Harding AH, Evans G. Human in vivo and in vitro studies on gastrointestinal absorption of titanium dioxide nanoparticles. Toxicol Lett. 2015;233(2):95-101. doi:10.1016/j.toxlet. 2014.12.005.

14. Powell JJ, Evans SM, Lomer MCE, Thompson RPH. What are intestinal pigment cells? Inflammatory Bowel Disease Monitor. 1999;1:71-4.

15. Sarmiento-Gonzalez A, Encinar JR, Marchante-Gayon JM, Sanz-Medel A. Titanium levels in the organs and blood of rats with a titanium implant, in the absence of wear, as determined by double-focusing ICP-MS. Anal Bioanal Chem. 2009;393(1):335-43. doi:10.1007/s00216-008-2449-2.

16. Sarmiento-Gonzalez A, Marchante-Gayon JM, Tejerina-Lobo JM, PazJimenez J, Sanz-Medel A. High-resolution ICP-MS determination of Ti, V, $\mathrm{Cr}, \mathrm{Co}, \mathrm{Ni}$, and $\mathrm{Mo}$ in human blood and urine of patients implanted with a hip or knee prosthesis. Anal Bioanal Chem. 2008;391(7):2583-9. doi:10.1007/s00216-008-2188-4.

17. Nuevo-Ordonez Y, Montes-Bayon M, Blanco-Gonzalez E, Paz-Aparicio J Raimundez JD, Tejerina JM, et al. Titanium release in serum of patients with different bone fixation implants and its interaction with serum biomolecules at physiological levels. Anal Bioanal Chem. 2011;401(9):2747-54. doi:10.1007/ s00216-011-5232-8.

18. Brun E, Barreau F, Veronesi G, Fayard B, Sorieul S, Chaneac C, et al. Titanium dioxide nanoparticle impact and translocation through ex vivo, in vivo and in vitro gut epithelia. Part Fibre Toxicol. 2014;11:13. doi:10.1186/1743-8977-11-131743-8977-11-13.

19. Geraets L, Oomen AG, Krystek P, Jacobsen NR, Wallin H, Laurentie M, et al. Tissue distribution and elimination after oral and intravenous administration of different titanium dioxide nanoparticles in rats. Part Fibre Toxicol. 2014;11(1):30. doi:10.1186/1743-8977-11-301743-8977-11-30.

20. Wang J, Zhou G, Chen C, Yu H, Wang T, Ma Y, et al. Acute toxicity and biodistribution of different sized titanium dioxide particles in mice after oral administration. Toxicol Lett. 2007;168(2):176-85.

21. Thoree V, Skepper J, Deere H, Pele LC, Thompson RP, Powell JJ. Phenotype of exogenous microparticle-containing pigment cells of the human Peyer's patch in inflamed and normal ileum. Inflamm Res. 2008;57(8):374-8. doi:10.1007/s00011-007-7216-х.

22. Jang MH, Kweon MN, Iwatani K, Yamamoto M, Terahara K, Sasakawa C, et al. Intestinal villous $M$ cells: an antigen entry site in the mucosal epithelium. Proc Natl Acad Sci U S A. 2004;101(16):6110-5. doi:10.1073/ pnas.04009691010400969101.

23. Howe SE, Lickteig DJ, Plunkett KN, Ryerse JS, Konjufca V. The uptake of soluble and particulate antigens by epithelial cells in the mouse small intestine. PLoS One. 2014;9(1), e86656. doi:10.1371/journal.pone. 0086656PONE-D-13-32521.

24. Theissmann R, Kluwig M, Koch T. A reproducible number-based sizing method for pigment-grade titanium dioxide. Beilste J Nanotechnol. 2014;5:1815-22. doi:10.3762/bjnano.5.192.

25. Lomer MC, Thompson RP, Powell JJ. Fine and ultrafine particles of the diet: influence on the mucosal immune response and association with Crohn's disease. Proc Nutr Soc. 2002;61(1):123-30. 
26. Peters RJB, Herrera-Rivera Z, Undas A, van der Lee M, Marvin H,

Bouwmeester $\mathrm{H}$, Weigel $\mathrm{S}$. Single particle ICP-MS combined with a data evaluation tool as a routine technique for the analysis of nanoparticles in complex matrices. J Agric Food Chem. 2014;62(27):6285-93.

27. Peters RJB, van Bemmel G, Herrera-Rivera Z, Helsper HPFG, Marvin HJP, Weigel $\mathrm{S}$, et al. Characterization of titanium dioxide nanoparticles in food products: analytical methods to define nanoparticles. J Agr Food Chem. 2014;62(27):6285-93. doi:10.1021/Jf5011885.

28. Fabricius AL, Duester L, Meermann B, Ternes TA. ICP-MS-based characterization of inorganic nanoparticles-sample preparation and off-line fractionation strategies. Anal Bioanal Chem. 2014;406(2):467-79. doi:10.1007/ s00216-013-7480-2

29. Aureli FD, D'Amato M, Raggi A, Cubadda F. Quantitative characterization of silica nanoparticles by asymmetric flow field flow fractionation coupled with online multiangle light scattering and ICP-MS/MS detection. J Anal At Spectrom. 2015;30:1266.

\section{Submit your next manuscript to BioMed Central and take full advantage of:}

- Convenient online submission

- Thorough peer review

- No space constraints or color figure charges

- Immediate publication on acceptance

- Inclusion in PubMed, CAS, Scopus and Google Scholar

- Research which is freely available for redistribution 